\title{
The Global Financial Crisis and the European Single Market: The end of integration?
}

Taufiq Choudhry $^{\mathrm{a}}$, Gerhard Kling ${ }^{\mathrm{b}}$ and Ranadeva Jayasekera ${ }^{\mathrm{a}}$

Using various versions of the Feldstein-Horioka $(\mathrm{FH})$ coefficient, we measure the timevarying degree of capital mobility and economic integration in the European Union. Prior research shows high correlation between domestic investment and savings implying low capital mobility. This surprising result has led to subsequent research on the 'FeldsteinHorioka puzzle'. Our empirical findings show that the puzzle is less puzzling with a coefficient of 0.52 in the period 1990-1995 in EU countries approaching its minimum value of 0.02 in the period 2003-2008. This clearly indicates that the FH coefficient is time-varying signalling a deepening of economic integration in the European Union. Yet, with the advent of the Global Financial Crisis the FH coefficient has increased to 0.26 underlining worrying signs of disintegration.

\footnotetext{
${ }^{\text {a }}$ University of Southampton

${ }^{\mathrm{b}}$ School of Oriental and African Studies, University of London
} 


\section{Introduction}

Apart from introducing the papers of the special issue on the Global Financial Crisis: European Financial Markets and Institutions, this paper takes a broader perspective by asking the question whether the Global Financial Crisis led to more or less economic integration in the European Union. This paper explores the economic and political consequences triggered by the Global Financial Crisis in the context of market integration or disintegration. The 13 papers of the special issue address various aspects of the Global Financial Crisis in Europe. Two papers investigate the spread of the crisis through the rating channel (Alsakka et al., 2014) and the liquidity channel (Petmezas and Santamaria, 2014). Arnold and Van Ewijk (2014) study the convergence of bank retail rates, and Molyneux et al. (2014) test the impact of safety net benefits on mergers and acquisitions (M\&As) in the European banking industry. Two papers explore corporate decisions amid the crisis with a focus on equity issues (Dissanaike et al., 2014) and cross-hedges (Gottschalk and Da Fonseca, 2014). Six papers investigate the impact of the crisis on various markets including European stock markets, the Euro exchange rate, sovereign CDS spreads, lending and the market for corporate control (Adcock et al., 2014; Choudhry and Jayasekera, 2014; Ehrmann et al., 2014; Gündüz and Kaya, 2014; Krainer, 2014; Weitzel et al., 2014). Finally, Werner's (2014) paper promises to solve the crisis by linking debt management with fiscal and monetary policy. These papers provide a detailed analysis of different markets serving as a basis for policy recommendations and future research. The editorial takes a step back and looks at the situation in Europe from a macroeconomic perspective. This aggregated view of the crisis tries to put things into perspective by addressing the wider impact of the Global Financial Crisis on the future of the European Single Market.

The history of the European Union is a history of political and economic integration leading to deeper economic ties, the synchronisation of policies and business cycles 
(Battilossi et al., 2010). The Single Market Act in 1987 with the aim of establishing the European Single Market paved the way for further integration. The common belief seems to be that globalisation and economic integration can be regarded as an unstoppable ongoing process. However, globalisation is not a 'one-way street'; the first phase of globalisation ended with WWI, and a 'deglobalization' period followed culminating in the Big Depression and WWII (Chase, 2004). Arguably, the Global Financial Crisis shook the financial system, and banks responded by withdrawing from foreign markets cutting their losses (e.g. HSBC withdrawal from the US retail market in 2011). Amid financial turmoil and fiscal austerity public opinion has turned against globalisation and economic integration. However, public pressure has not yet led to more protectionism based on legal measures (Bussière et al., 2011). For a long time, political economists and business strategists argued about 'the end of the nation state' and the inevitable rise of the multinational corporation (Kobrin, 2001; Ohmae, 1995). The Global Financial Crisis has shifted the relationship between multinationals and nation states. The nation state seems to fight back.

This paper applies various versions of the Feldstein-Horioka $(\mathrm{FH})$ coefficient to quantify the extent of economic integration in terms of capital mobility within and outside the European Union (Feldstein and Horioka, 1980). Our main findings indicate that capital mobility increased from 1990 to 2008 in EU member states but also in non-EU member states. The Global Financial Crisis coincided with a substantial reduction of capital mobility. This fundamental change in the direction of market integration is more pronounced in EU member states than in other countries.

The paper is structured as follows. Section two briefly highlight the data source and defines the variables. Section three provides our empirical findings followed by a discussion and concluding remarks. 


\section{Data and definition of variables}

Using the World Development Indicators for the period 1990 to 2012, we determine gross domestic investment (INV) and savings ratios (SAV) relative to GDP for 252 countries. Based on membership as of 2014, we distinguish between EU member states and other countries (EU dummy). Empirical models refer to the two sets of countries to assess the impact of EU membership on capital mobility. We also include a dummy for PIIGS countries (i.e. Portugal, Ireland, Italy, Greece and Spain), which were severely affected by the crisis. To measure the impact of the crisis, we define a dummy variable (CRISIS), which takes value one after 2008 and zero otherwise. We follow Weitzel et al. (2014) in defining the crisis period in Europe.

Feldstein and Horioka (1980) refer to the mediating effect of openness defined as exports plus imports relative to GDP (OPEN), which is considered in our study. Moreover, several studies point to the importance of country size. In an extended model, we incorporate country size measured as the natural logarithm of GDP (SIZE) (Harberger, 1980; Murphy, 1984; Petreska and Mojsoska-Blazevski, 2013; Sinn, 1992). Following Feldstein and Horioka (1980), we also use a simultaneous equation model, which accounts for variables that influence savings such as population growth rate (POP) (Petreska and Mojsoska-Blazevski, 2013). To capture the impact of the Global Financial Crisis, we also include countries' primary deficits (DEF) and debt relative to GDP (DEBT). Both variables might affect savings behaviours, as they indicate the current and long-term financial state of the country. Finally, in a separate equation gross domestic investment might depend on foreign direct investment (FDI) and portfolio investment relative to GDP (PORT). Accordingly, we modify the simultaneous equation model, as most of the variables used by Feldstein and Horioka (1980) are not available for all countries. In addition, our aim is to capture the impact of the Global 
Financial Crisis; thus, variables of short and long-term financial sustainability and hot money (i.e. portfolio investment) might be relevant.

In addition, we define interaction terms with domestic saving rates to capture the impact of the crisis on the FH coefficient (CRISIS_SAV). We do the same for EU membership (EU_SAV) and PIIGS countries (PIIGS_SAV). Finally, we consider an interaction between EU membership and the crisis (EU_CRISIS) and the interaction with domestic saving rates (EU_CRISIS_SAV).

In line with Feldstein and Horioka (1980), we take the mean of variables over a certain time period. Later work on the Feldstein-Horioka puzzle uses panel regressions (Petreska and Mojsoska-Blazevski, 2013). Apart from taking the mean over the whole investigation period, we also conduct rolling regressions based on overlapping five-year windows, which is close to panel regressions without adding two much noise of annual data. For the simultaneous equation models, we deviate from Feldstein and Horioka (1980) and use a panel data approach to increase the sample size.

\section{Empirical findings}

The analysis starts by replicating the model in equation (1) described in Feldstein and Horioka (1980), where gross domestic investment rates (INV) are explained by domestic savings rates (SAV). Adding an error term with the usual assumptions and making it explicit that average rates over the whole period are taken, equation (1) captures our first model.

$$
\sum_{j=1}^{T} I N V_{i j}=\alpha+\beta \sum_{j=1}^{T} S A V_{i j}+\varepsilon_{i}, \quad \varepsilon_{i} \sim^{i i d} N\left(0, \sigma^{2}\right), i=1,2, \ldots, N
$$

For the period 1990 to 2012 and including all countries, equation (1) exhibits a beta coefficient of 0.12 , which is significantly smaller than the coefficient reported by Feldstein and Horioka (1980). Moreover, the adjusted R-squared is only 0.11; again being substantially 
smaller than in Feldstein and Horioka (1980). How can this discrepancy be explained? Feldstein and Horioka (1980) refer to the period 1960 to 1974 . It is likely that the FH coefficient underwent considerable change over time. To account for time-varying coefficients, we run rolling regression based on equation (1) for overlapping five-year windows starting in 1990. Figure 1 plots the FH coefficient for EU countries and non-EU countries for different periods. It is evident that the FH coefficient has declined over time; however, since the Global Financial Crisis hit the markets, the coefficient seems to increase again. This surge is more pronounced in EU member states.

(Insert Figure 1)

Feldstein and Horioka (1980) suggest a modified model (see equation (2)) that accounts for the degree of openness defined as exports plus imports divided by GDP (OPEN). Hence, we define an interaction effect between openness and saving rates (OPEN_SAV). Again we determine average values in line with Feldstein and Horioka (1980).

$$
\sum_{j=1}^{T} I N V_{i j}=\alpha+\beta_{0} \sum_{j=1}^{T} S A V_{i j}+\beta_{1} \sum_{j=1}^{T} S A V_{i j} \sum_{j=1}^{T} O P E N_{i j}+\varepsilon_{i}
$$

Compared to equation (1), findings do not change substantially; hence, the minimum is reached in the period 2003 to 2008, and the financial crisis coincides with an increase in the FH coefficient. This increase is more severe in EU-countries.

Using OLS to estimate equations (1) and (2) hinges on the assumption of strict exogeneity, which is very unlikely to hold, as savings and investment rates might depend on other country-specific factors (Feldstein and Horioka, 1980; Harberger, 1980; Petreska and Mojsoska-Blazevski, 2013; Sinn, 1992). Hence, we follow Feldstein and Horioka (1980) and propose a simultaneous equation model. Yet, we adopt a panel data approach in line with Petreska and Mojsoska-Blazevski (2013) to overcome the limitations of a small sample size given the increase in parameters demanded by a simultaneous equation model. In addition, 
we modify the explanatory variables (instruments) in the simultaneous equation model to account for the impact of the Global Financial Crisis. In particular, we propose a modified equation (2), which also incorporates the size effect discussed by Murphy (1984). This first equation links investments to savings and thus contains the FH coefficient. The second equation suggests that investment might be driven by FDI and portfolio investment, whereas the third equation postulates that savings rates depend on population growth, deficits, and public debt. The basic model (MODEL A in Table 1) has the following structure.

$$
\begin{gathered}
I N V_{i t}=\alpha+\beta_{0} S A V_{i t}+\beta_{1} O P E N_{-} S A V_{i t}+\gamma_{0} O P E N_{i t}+\gamma_{1} S I Z E_{i t}+\varepsilon_{i t} \\
I N V_{i t}=\delta_{0}+\delta_{1} F D I_{i t}+\delta_{2} P O R T_{i t}+u_{i t} \\
S A V_{i t}=\theta_{0}+\theta_{1} P O P_{i t}+\theta_{2} D E F_{i t}+\theta_{3} D E B T_{i t}+w_{i t}
\end{gathered}
$$

MODEL B incorporates the EU dummy and the interaction with savings rates (EU_SAV) as well as the PIIGS dummy and the interaction with savings rates (PIIGS_SAV). The EU dummy is significant on the $95 \%$ level of confidence pointing to reduced investment rates in EU countries. The interaction effect with savings rates (EU_SAV) is positive suggesting a stronger correlation between domestic investment rates and savings rates, which indicates less capital mobility compared to non-EU countries. The PIIGS dummy and interaction term are not significant; thus, the EU impact is not restricted to crisis countries. MODEL $\mathrm{C}$ adds the impact of the CRISIS on investment rates, which is negative as expected, and the interaction effect with savings rates (CRISIS_SAV), which is positive and significant. Accordingly, the crisis not only dampens investment rates but also reduces capital mobility. MODEL D tries to combine the effect of EU membership during the crisis (EU_CRISIS and EU_CRISIS_SAV); however, the combined effect is not significant. So we can conclude that EU countries seem to have lower investment rates and a higher dependence on domestic savings in the period from 1990 to 2012. Furthermore, the crisis led to less capital mobility. 
We compared OLS and three-stage least squares estimates using a Hausman test. The Hausman test rejects the null hypothesis that the differences in coefficient estimates are not systematic with a test statistic of 8.11 and a p-value of 0.04 . In addition, exploring correlation coefficients between residuals of the three equations shows correlation coefficients of 0.75 between the residuals of the first and second equations. These results suggest using a threestage least squares estimation, which we report in Table 1.

(Insert Table 1)

\section{Discussion}

Our findings show that the Feldstein-Horioka puzzle vanishes by considering a more recent time period and allowing time-varying Feldstein-Horioka coefficients. In fact, capital mobility between markets increased until the start of the Global Financial Crisis followed by a significant decline afterwards. This turning point seems to be more pronounced in EU countries suggesting less economic integration in Europe after the crisis. The question is whether these findings should concern us. Disintegration of the European market in terms of cross-border capital flows suggests a higher dependency on domestic savings, which might reduce political cohesion in Europe. However, one can argue that a reduction of capital mobility might enhance economic stability giving more control to nation states. Whether these early signs of disintegration will be followed by more severe economic and political consequences requires further research.

\section{Acknowledgements}

We also would like to thank the Money Macro and Finance Research Group for their support in organising this conference. We are very pleased and grateful that Professor James Lothian (Fordham University, USA) delivered the keynote speech, and Professor Charles Goodhart 
(London Business School) presented the lunch time seminar. We are very grateful to our sponsors, the Journal of International Money and Finance, the Money Macro and Finance Research Group, the Bank of England, Bloomberg and the School of Management, University of Southampton. 


\section{References}

Battilossi, S., Foreman-Peck, J.S. and Kling, G. (2010). Business cycles and economic policy, 1945-2007. In: Broadberry, S. and O'Rourke, K.H. eds. Cambridge Economic History of Modern Europe : 1870 to the Present, Vol. 2. Cambridge Economic History of Modern Europe , Cambridge: Cambridge University Press, 360-389.

Bussière, M., Pérez-Barreiro, E., Straub, R. and Taglioni, D. (2011) Protectionist Responses to the Crisis: Global Trends and Implications, The World Economy 34(5): 826-852.

Chase, K.A. (2004) Imperial protection and strategic trade policy in the interwar period. Review of International Political Economy 11: 177-203.

Feldstein, M. and Horioka, C. (1980) Domestic saving and international capital flows, Economic Journal 90: 314-329.

Harberger, A. (1980). Vignettes on the world capital market. American Economic Review, 70: $331-337$.

Kobrin, S. (2001) Sovereignty@Bay: Globalisation, Multinational Enterprise, and the International Political System, in Rugman, A. and Brewer, T. eds., The Oxford Handbook of International Business, Oxford University Press.

Murphy, R. G. (1984). Capital mobility and the relationship between saving and investment rates, Journal of International Money and Finance, 3: 327-342.

Ohmae, K. (1995) The End of the Nation-State: The Rise of Regional Economies. New York: Free Press.

Petreska, D. and Mojsoska-Blazevski, N. (2013) The Feldstein-Horioka puzzle and transition economies, Economic Annals 63: 23-45. 
Figure 1. Estimated Feldstein-Horioka coefficients for different time periods

Figure 1 plots the FH coefficient for EU countries and non-EU countries for different periods.

The regression model refers to equation (1) estimated using rolling regressions with five-year windows.

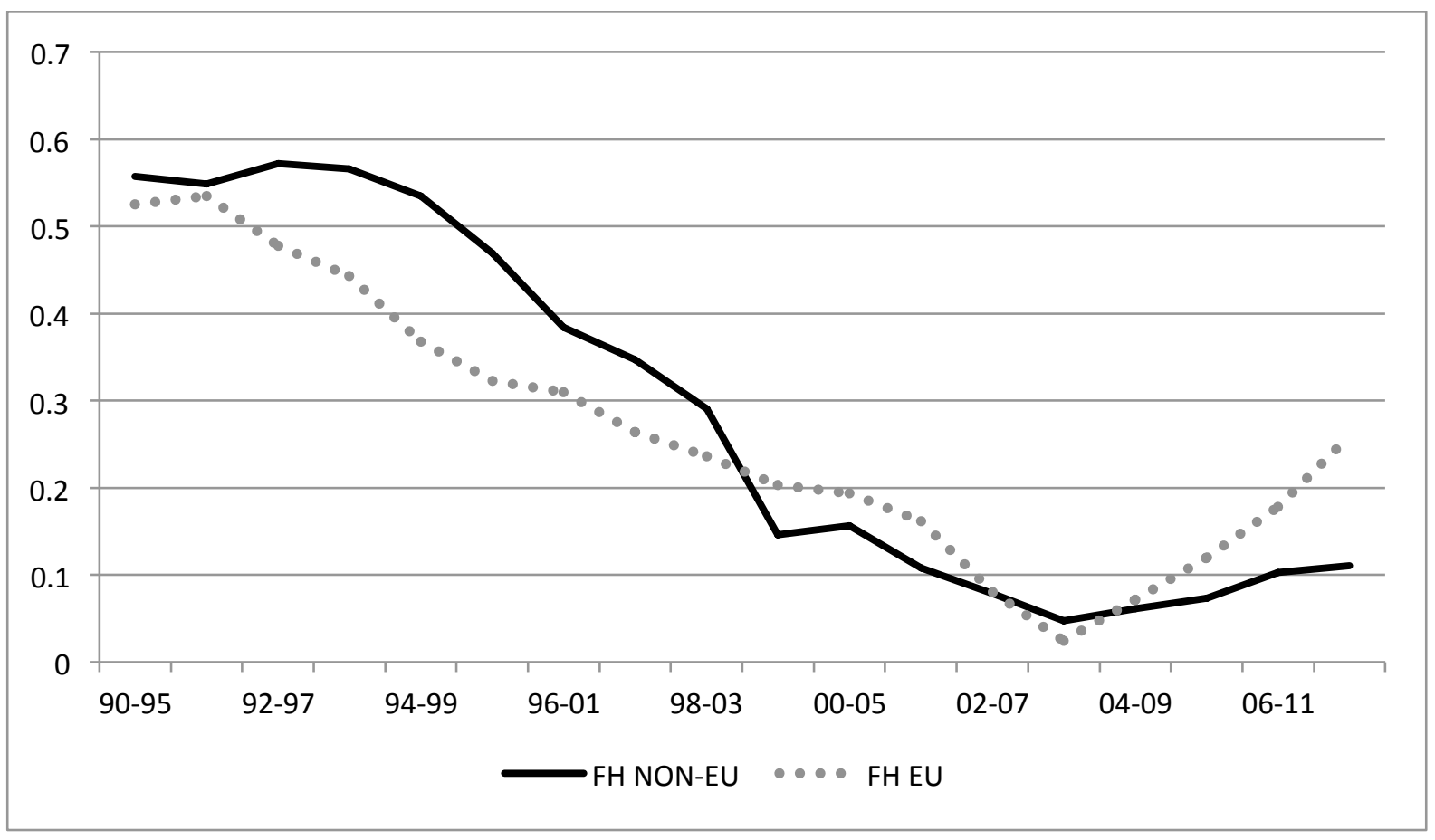




\section{Table 1. Results of the simultaneous equation model}

We estimate the three equations of the simultaneous equation model described in equation (3) using three-stage least squares. The table reports significance levels, where $*, * *$ and $* * *$ indicate significance on the $5 \%, 1 \%$ and $0.1 \%$ level respectively. The table contains the number of observations $(\mathrm{N})$ and information criteria (AIC, BIC).

\begin{tabular}{|c|c|c|c|c|c|}
\hline MODEL & A & $B$ & $\mathrm{C}$ & $\mathrm{D}$ & $E$ \\
\hline \multicolumn{6}{|c|}{ First equation } \\
\hline SAV & 0.087 & 0.067 & 0.006 & 0.051 & -0.068 \\
\hline OPEN & $-0.031 * * *$ & $-0.040 * * *$ & $-0.039 * * *$ & $-0.035 * *$ & $-0.048 * * *$ \\
\hline OPEN_SAV & $0.001 * * *$ & $0.002 * * *$ & $0.002 * * *$ & $0.001 * * *$ & $0.002 * * *$ \\
\hline SIZE & -0.007 & -0.028 & -0.031 & -0.047 & \\
\hline EU & & $-2.615^{*}$ & $-2.290 *$ & $-3.154 *$ & $-2.041^{*}$ \\
\hline EU_SAV & & $0.135^{* *}$ & $0.120 *$ & $0.162^{*}$ & $0.121^{* *}$ \\
\hline PIIGS & & 0.654 & 1.365 & 1.058 & \\
\hline PIIGS_SAV & & -0.007 & -0.038 & -0.022 & \\
\hline CRISIS & & & $-3.513 * * *$ & $-3.538 * *$ & $-3.850 * * *$ \\
\hline CRISIS_SAV & & & $0.177^{* * *}$ & $0.182 * * *$ & $0.193 * * *$ \\
\hline EU_CRISIS & & & & 2.84 & \\
\hline EU_CRISIS_ & & & & -0.155 & \\
\hline Constant & $21.148 * * *$ & $22.106 * * *$ & $23.405^{* * *}$ & $22.754 * * *$ & $24.292 * * *$ \\
\hline \multicolumn{6}{|c|}{ Second equation } \\
\hline FDI & 0.023 & 0.028 & 0.031 & 0.034 & 0.028 \\
\hline PORT & -0.184 & -0.152 & -0.257 & -0.178 & -0.289 \\
\hline Constant & $22.594 * * *$ & $22.571 * * *$ & $22.560 * * *$ & $22.545^{* * *}$ & $22.575^{* * *}$ \\
\hline \multicolumn{6}{|c|}{ Third equation } \\
\hline POP & $0.249^{*}$ & $0.299^{*}$ & $0.299 *$ & $0.299 *$ & $0.278^{*}$ \\
\hline DEBT & $-0.019 * * *$ & $-0.018 * * *$ & $-0.017 * *$ & $-0.016 * *$ & $-0.020 * * *$ \\
\hline DEF & $0.621 * * *$ & $0.642 * * *$ & $0.648 * * *$ & $0.652 * * *$ & $0.620 * * *$ \\
\hline Constant & $23.730 * * *$ & $23.664 * * *$ & $23.649 * * *$ & $23.569 * * *$ & $23.770 * * *$ \\
\hline \multicolumn{6}{|l|}{ Statistics } \\
\hline aic & 16746.52 & 17212.74 & 17397.6 & 17316.63 & 17555.85 \\
\hline bic & 16805.91 & 17291.94 & 17486.69 & 17415.63 & 17630.1 \\
\hline $\mathrm{N}$ & 1043 & 1043 & 1043 & 1043 & 1043 \\
\hline
\end{tabular}

